\title{
Insect pollination enhances yield stability in two pollinator-dependent crops
}

\author{
Pablo L. Hünicken a,b, ", Carolina L. Morales c, Marcelo A. Aizen c, Georg K.S. Anderson ${ }^{\text {d, }}$

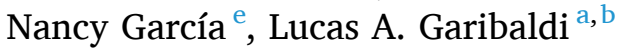 \\ ${ }^{a}$ Universidad Nacional de Río Negro. Instituto de Investigaciones en Recursos Naturales, Agroecología y Desarrollo Rural, Río Negro, Argentina \\ ${ }^{\mathrm{b}}$ Consejo Nacional de investigaciones Científicas y Técnicas. Instituto de Investigaciones en Recursos Naturales, Agroecología y Desarrollo Rural, Río Negro, Argentina \\ ${ }^{\mathrm{c}}$ Grupo de Ecología de la Polinización, Instituto de Investigaciones en Biodiversidad y Medioambiente (INIBIOMA), Universidad Nacional del Comahue-CONICET, San \\ Carlos de Bariloche, Río Negro, Argentina \\ ${ }^{\mathrm{d}}$ Centre for Environmental and Climate Research, Lund University, Sweden \\ ${ }^{\text {e } C e n t r o ~ P Y M E, ~ A g e n c i a ~ d e ~ D e s a r r o l l o ~ E c o n o ́ m i c o ~ d e l ~ N e u q u e ́ n, ~ N e u q u e ́ n, ~ A r g e n t i n a ~}$
}

\section{A R T I C L E I N F O}

\section{Keywords:}

Apis mellifera

Fruit production

Honey bee

Malus domestica

Pollination variability

Pyrus communis

Spatial stability

Temporal stability

\begin{abstract}
A B S T R A C T
One of the most important challenges facing global agriculture is to ensure an adequate, stable food supply while conserving soil, water and biodiversity. The yield stability of pollinator-dependent crops, such as pear and apple, can be negatively affected by variability of the pollination service, which in turn can reduce mean yield. We explored how mean crop yield and yield variability were affected by pollinators and variability in their provision of the pollination service. Over four seasons we conducted a manipulative experiment in six pear and eight apple farms; fruit set (i.e., no. fruits/ no. flowers) was compared between flowers exposed to pollinators and those excluded from pollinators. We also recorded pollinator visitation rate to exposed flowers. We estimated the mean levels and spatial and temporal variability of both pollinator visitation and yield response by calculating the mean values per farm and the spatial (i.e., across trees within farm) and temporal (i.e., across seasons within farm) coefficients of variation (CV) for visitation rate and fruit set. Despite homogeneous irrigation and fertilization, we found strong variability in fruit set in both crops (pear spatial and temporal CV: 0.57 and 0.4 , respectively; apple: 0.62 and 0.52). Pollinator exclusion reduced mean fruit set considerably in both crops (pears: a reduction of 50\%, apples: 71-92\%), and increased spatial and temporal variability (pears: $296 \%$ and 197\% for spatial and temporal variability, respectively; apples: $385 \%$ and $329 \%$ ). Visitation rates in pears were positively associated with mean fruit set and negatively related to its spatial CV. Also, in this crop we found a positive relation between the spatial $\mathrm{CV}$ of visitation rate and fruit set. However, there was no evidence that visitation rate in open-pollinated apple flowers affected either mean fruit set or its spatial or temporal variability. Apple trees received one order of magnitude more visits per flower than pear trees, suggesting that in this system the pollination service meets the pollination demand of the apple crop. Overall, our results highlight the importance of management practices that prioritize pollination service, thus ensuring a high, stable yield.
\end{abstract}

\section{Introduction}

Ensuring a stable, adequate food supply while minimizing environmental degradation is one of the most important challenges facing global agriculture today. In fact, conventional intensification of agriculture has been successful in increasing yields in the short term, but this has come at the cost of high external subsidies and the deterioration of ecosystem functions like nutrient cycling, biological pest control and pollination (Krebs et al., 1999; Matson et al., 1997; Foley et al., 2005). In this way, conventional agriculture compromises future yields, decreasing their spatial and temporal stability (Deguines et al., 2014). Improving knowledge of the relation between ecosystem functions and crop yield is therefore key to dealing with the challenges of increasing crop productivity and stability.

Globally, $\sim 70 \%$ of cultivated species depend to some extent on insect pollination (Klein et al., 2007). Furthermore, global agriculture has become increasingly pollinator-dependent, cropland expansion having been driven mainly by increasing the area devoted to

\footnotetext{
* Correspondence to: Anasagasti 1463, San Carlos de Bariloche, Río Negro, Argentina.

E-mail addresses: pablohunicken@gmail.com, phunicken@unrn.edu.ar (P.L. Hünicken).
} 
pollinator-dependent crops (Aizen et al., 2008, 2009). Although the importance of abundant, diverse pollinator assemblages for the yield of pollinator-dependent crops has been amply confirmed (Garibaldi et al., 2013; Dainese et al., 2019), their role in crop stability has received less attention (e.g., Kremen et al., 2004, Klein, 2009, Geeraert et al., 2020). Two studies have reported patterns that point to animal pollination as a driving factor of yield stability in pollinator-dependent crops. First, Garibaldi et al. (2011a) found on a global scale that lower mean yield and higher temporal variability were associated with a higher degree of pollination dependence in crops. Second, Deguines et al. (2014) reported patterns on a country scale of reduced mean yield and higher spatial variability in highly pollinator-dependent crops along gradients of increasing agricultural intensification. Therefore, addressing how pollination function affects crop yield and stability over space and time is of paramount importance.

This question should take into account not only how crop yields and their spatial and temporal variability respond to the provision of pollination service (i.e., mean values), but also how these responses are influenced by variability in the pollination service itself. For instance, Geeraert et al. (2020) showed that non-Apis diversity increased temporal stability in coffee yields, while Klein (2009) showed that lower variability in bee richness close to forest edges was associated with high coffee yields and reduced spatial yield variability. These results highlight the influence of pollinator diversity and its spatio-temporal stability on crop yields and their spatial and temporal stability. However, since under the current dominance of conventional agriculture a large proportion of commercial crops rely almost exclusively on few or even a single pollinator species (mostly honeybees, Klein et al., 2007), we need a broader conceptual framework within which to study the variation in crop yields associated with variation in the quantitative aspect of pollination function (e.g., pollinator abundance or visitation frequency). Such a framework could be applied to different crop systems, regardless of species diversity or composition. Here we applied a conceptual framework that enabled us to simultaneously evaluate the effect of spatial and temporal variability in pollinator visits on spatial and temporal variability in fruit set in the pear and apple, two crops with great pollinator dependence (Klein et al., 2007).

Yield typically increases asymptotically with the addition of resources such as nutrients, water or pollen (Fig. 1, Rubio et al., 2003). The shape of this response has several consequences. First, within a certain range, increases in mean resource supply are expected to enhance mean yield (Fig. 2-A1). Second, increases in mean resource supply are expected to reduce variability in crop yield (Fig. 2-B1). Third, for a certain mean resource supply, mean yield is lower when resource supply variability is higher (higher coefficient of variation - hereafter CV) than expected, for a stable resource supply (lower CV); this is a consequence of what is known as Jensen's inequality (Fig. 2-C1, Ruel and Ayres, 1999). Finally, a more direct and less empirically assessed consequence is that yield variability is expected to increase with high variability of

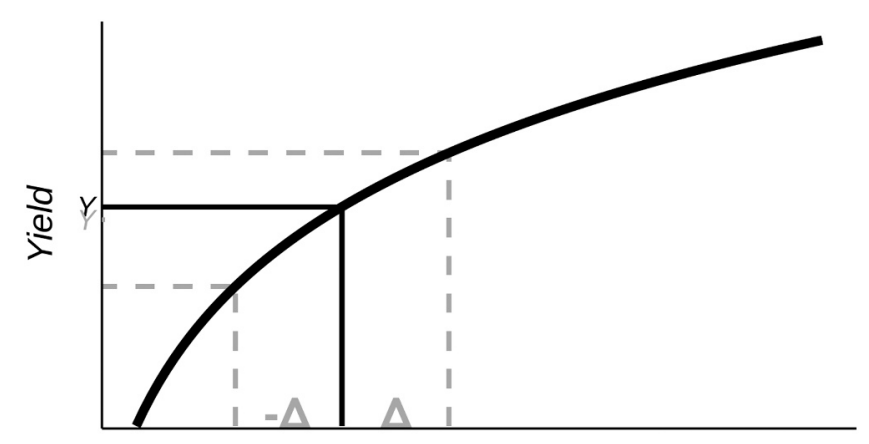

Resource

Fig. 1. - General relation of yield (e.g., fruit $\mathrm{x}$ flower ${ }^{\wedge}-1$ ) to resource availability. resource supply (Fig. 2-D1). Although the enhanced yields at high pollination service levels predicted by Fig. 2-A1 have been broadly confirmed (Aizen et al., 2009; Garibaldi et al., 2013; Klein et al., 2007), few studies have tested the other three relationships (Fig. 2-B1,C1,D1). Since pollination is not as frequently managed as fertilization or watering, yield variation in pollinator-dependent crops could be more strongly linked to variation in pollen supply (Garibaldi et al., 2011a, 2011b).

We aim to explore the influence of pollinators and variability in the provision of pollination service on mean crop yield and its variability. To this end, we constructed a 4-year time series of pollinator visitation rates and fruit set in the pear and apple. We evaluated the effect of pollinator exclusion and mean levels of visitation rate, plus the spatial and temporal variability of visitation rate, on fruit set mean levels and spatial and temporal variability of fruit set. We expect that mean fruit set will increase with pollinator access to flowers and mean visitation rate (Fig. 2-A1), and decrease with the visitation rate spatial and temporal CV (Fig. 2-C1). In addition, we expect that fruit set CV will decrease with pollinator access to flowers and mean visitation rate (Fig. 2-B1), and increase with visitation rate spatial and temporal CV (Fig. 2-D1).

\section{Material and methods}

\subsection{Study system}

This study was carried out during the austral growing seasons of 2015-2016, 2016-2017, 2017-2018 and 2018-2019 (hereafter 2016, 2017, 2018 and 2019, respectively), from flowering in September to harvesting in March. The study area is an irrigation valley that lies in the arid region of northern Argentine Patagonia, known as the 'Alto Valle de Río Negro y Neuquén' (Cabrera and Willink, 1973). This region concentrates $\sim 90 \%$ of Argentinean pear and apple production (Avellá et al., 2018). Typically, the farms are managed conventionally, with high use of pesticides and fertilizers. Watering is achieved by completely flooding the plot, and tillage of top soil between tree rows is a recurrent practice. Pollination management involves the deployment of honeybee (Apis mellifera) hives around the orchards. In December, chemical thinning is carried out on the apple trees in order to reduce the development of small fruits. The abundance of wild pollinators during the flowering period of pears and apples is close to zero on these farms (Geslin et al., 2017; Hünicken et al., 2020; Pérez-Méndez et al., 2020).

The farms selected are near the locality of 'San Patricio del Chañar', Neuquén province (approx. $38^{\circ} 37^{\prime} \mathrm{S}, 68^{\circ} 18^{\prime} \mathrm{W}$, Fig. S1). We took measurements on six pear farms and eight apple farms, in ten trees per farm in 2016, 2018 and 2019 and five trees per farm in 2017. All the farms of each crop were separated from each other by at least $1.5 \mathrm{~km}$. All farms used field flooding for irrigation (except one, which used drip irrigation) and applied the same fertilizers (manure and foliar fertilizer). The trees on each farm were distributed in rows, each row containing a single variety, and alternating rows were of different varieties. All selected trees were from the same row, so the effect of distance to another variety was controlled for. The crop varieties selected were Packhams' Triumph for pear, and Red Delicious for apple, two typical varieties grown in this region. Both crops have perfect flowers (i.e., female and male organs in the same flower); they are largely selfincompatible, and depend on cross-pollination to set the fruit (Jackson, 2003; Maccagnani et al., 2003; Ramírez and Davenport, 2013). According to the categories of Klein et al. (2007), both crops are greatly dependent on pollinators (i.e., production decreases by $40-90 \%$ in the absence of pollinators). Although the flowers of both crops have nectaries, the amount and concentration of sugar differs: apple flowers produce a higher volume of nectar with higher sugar concentration than pear flowers (Farkas and Orosz-Kovács, 2003; Jackson, 2003; Maccagnani et al., 2007; Díaz et al., 2013). 
A

1
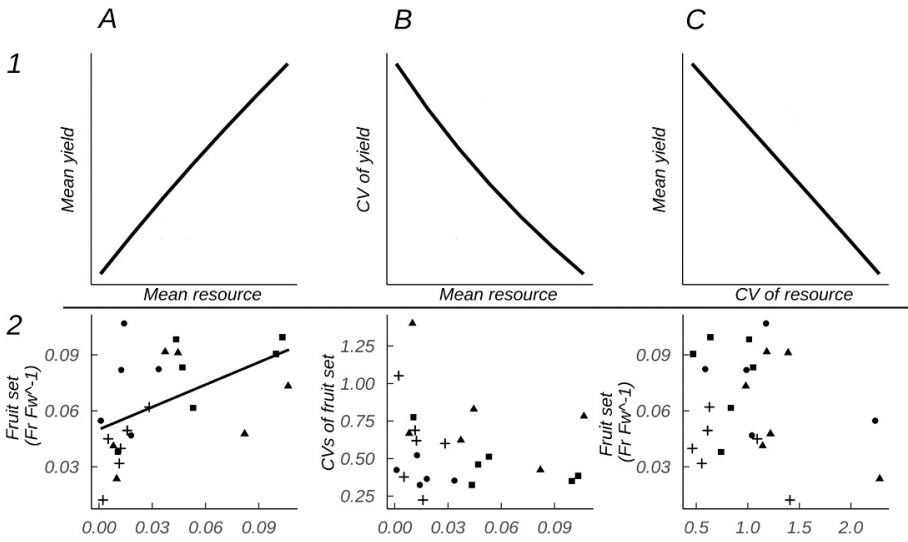

$\begin{array}{llll}0.00 & 0.03 & 0.06 & 0.09\end{array}$
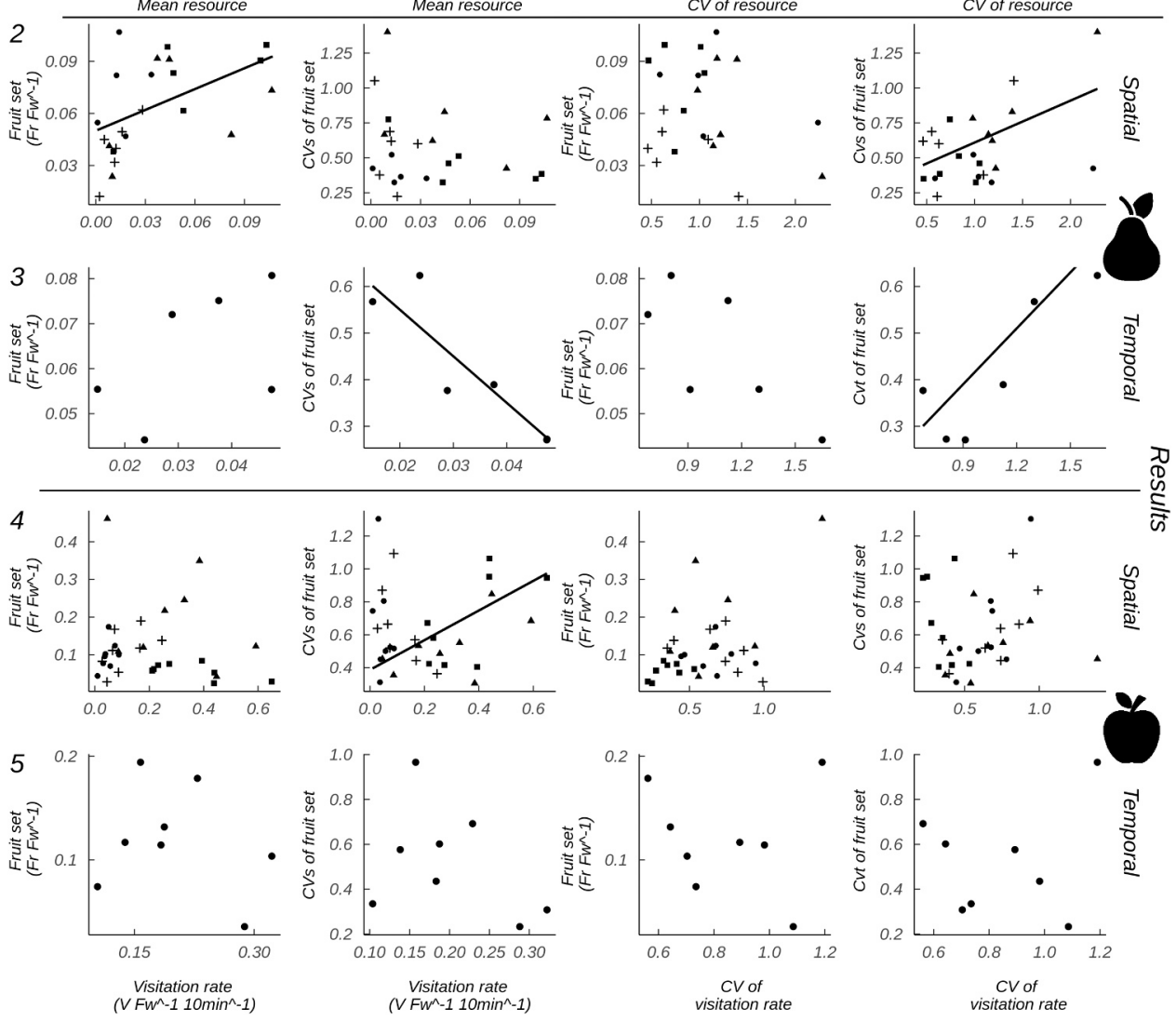

\subsection{Pollination treatment}

To evaluate the effect of insect pollination, on each tree we excluded a number of pear and apple flowers from visits (pear mean \pm SD: $22.6 \pm 0.5$; apple: $18.1 \pm 0.6$ ) (exclusion treatment), and marked a number of exposed pear and apple flowers (pear mean \pm SD: $65 \pm 2$; apple: $46.6 \pm 0.9$ ) (open treatment). Sampled inflorescences were randomly located in the middle section of each tree. Exclusion was performed by covering 2 or 3 inflorescences with tulle bags (mesh size $2 \mathrm{~mm}$ ). In total we followed 8054, 4631, 4522 and 4829 pear flowers and 4793, 2909, 4578 and 5830 apple flowers during seasons 2016, 2017, 2018 and 2019, respectively. When fruits ripened in February, we counted the number that had developed from flowers assigned to our open and exclusion treatments; this enabled us to estimate fruit set, defined as the ratio of developed fruits to tagged flowers. Beehives were placed on the road that separates the pear and apple trees, so distance to the hives was similar for both tree types.

\subsection{Visitation rate}

During each flowering season we surveyed flower visitation 2-6 times in all focal trees, between 9:00 am and 6:00 pm, when the temperature exceeded $15^{\circ} \mathrm{C}$. Two methods were used to assess visitation rate. In 2016 and 2017 we took measurements only in the flowers tagged for the 'open' treatment and recorded the number of visits made by each
Fig. 2. - Predictions and results of the effect of and $\mathrm{CV}$ ) of pears and apples. Row 1 shows the relations predicted of (A) Mean yield to mean resource. (B) Coefficient of variation in yield to mean resource. (C) Mean yield to coefficient of variation of resource. (D) Coefficient of variation of yield to coefficient of variation of resource. Please note that the relations predicted are not linear. Rows 2-3: results for pear; 4-5: apple. Rows 2 and 4 reflect the data used for the 'spatial variation models' and each symbol refers to a season (cross: 2016, circle: 2017, triangle: 2018, square: 2019). Rows 3 and 5 reflect the data used for the 'temporal variation models'. Regression lines were added when the effect of visitation rate (mean or CV) is statistically significant ( $\mathrm{p}<0.05)$. Visitation rate $=$ Visit $\times$ Flower $\_1 \times 10$ min ^ -1 , Fruit set $=$ Fruit $x$ Flower ${ }^{\wedge}-1$. Note the difference in scales in the $\mathrm{x}$ and $\mathrm{y}$ axes between rows. visitation rate (mean and CV) on fruit set (mean

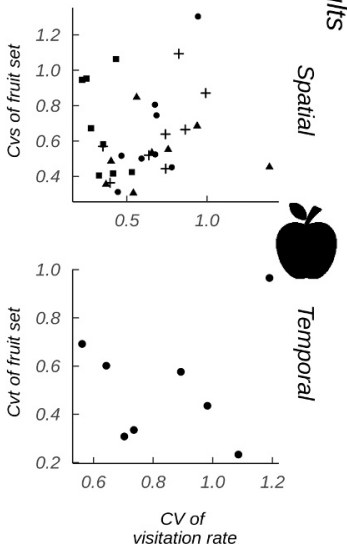

insect over $10 \mathrm{~min}$. Because of the low sensitivity of this method in detecting visits, in 2018 and 2019 we took measurements in a larger number of randomly selected inflorescences, counting the number of flowers and recording the number of visits made by each insect over $10 \mathrm{~min}$. We categorized the visitors into the following functional groups: A. mellifera, bumblebees (Bombus sp.), hoverflies (Syrphidae), and other species. Over the first two seasons a mean \pm SD of $16.7 \pm 0.3$ and $9.6 \pm 0.2$ flowers per tree were observed in each census on pear and apple, respectively. Over the second two seasons a mean \pm SD of $34.1 \pm 0.8$ and $37 \pm 1$ flowers per tree were observed in each census on pear and apple, respectively.

\subsection{Spatial and temporal variability}

For both the variables measured (fruit set and visitation rate), we calculated the mean value across trees for each farm and season. In addition, we calculated the respective coefficients of variation (CV) by dividing the standard deviation by the mean value. We called this new variable spatial $\mathrm{CV}$, since it reflects variation among trees within a farm. We used the mean values for each farm in each year to calculate the mean value by farm over the four seasons, and its respective CV. The latter was called temporal $\mathrm{CV}$, as it reflects the variation among seasons within a farm. The scales selected (i.e., for both spatial and temporal variation within a farm) are relevant from an agronomic perspective, since producers are able to modify possible sources of this variation via 
changes in their management practices.

\subsection{Statistical analyses}

We estimated linear mixed-effects models (LMM) and linear models (LM) with the 'nlme' package and 'base' package of $\mathrm{R}$ program, respectively (Pinheiro et al., 2016; R Core Team, 2018). We included the factor "Season" as a composite variable to control for climatic effects. Climatic variables for the years of our study are described in Table S1.

To analyze the effects of pollination on mean fruit set and its spatial variability, we performed two sets of models (Table 1 and S2). In the first we tested the effect of exclusion treatment, season, and the interaction between these variables, on mean fruit set and spatial CV of fruit set. In the second set of models, using data from only exposed flowers, we tested the effect of mean visitation rate, season, and the interaction between these variables, on mean fruit set and spatial CV of fruit set. We also tested the effect of visitation rate $\mathrm{CV}$, season, and the interaction between these variables on mean fruit set and its spatial CV. Farm was set as a random factor in all models.

Regarding the effects of pollination on the levels and temporal variability of fruit set, we also performed two sets of models (Table 2 and S3). In the first we tested the effect of exclusion treatment on fruit set (mean and CV), and Farm identity was modeled as a random effect. In the second set of models, using data from only exposed flowers, we tested the effect of visitation rate (mean and CV) on fruit set (mean and CV).

The assumptions of normality, independence and homoscedasticity of all the models were visually checked (QQ-plot, predicted vs. residuals and histogram of residuals). Some variables were log transformed to achieve normality. We tested the significance $(\mathrm{p}<0.05)$ of variables using the Anova function of 'car' package (Fox and Weisberg, 2011). When interaction was not significant, it was removed from the final model in order to make more accurate estimates of coefficients.

\section{Table 1}

- Chisq values of each predictor variable of the 'spatial variation' models. Chisq and $\mathrm{p}$ values were calculated with the Anova function of the car package. Chisq values whose $\mathrm{p}$-values are lower than 0.05 are shown in bold type; chisq values whose p-values are lower than 0.1 are in italics. In the exclusion treatment model of apples, fruit set was log transformed to achieve normality.

\begin{tabular}{|c|c|c|c|c|c|}
\hline & \multirow[b]{2}{*}{ Predictor } & \multicolumn{2}{|l|}{ Pear } & \multicolumn{2}{|l|}{ Apple } \\
\hline & & $\begin{array}{l}\text { Fruit } \\
\text { set }\end{array}$ & $\begin{array}{l}\text { Spatial } \\
\text { CV of } \\
\text { fruit set }\end{array}$ & $\begin{array}{l}\text { Fruit } \\
\text { set }\end{array}$ & $\begin{array}{l}\text { Spatial CV } \\
\text { of fruit set }\end{array}$ \\
\hline \multirow{3}{*}{$\begin{array}{l}\text { Exclusion } \\
\text { treatment } \\
\text { models }\end{array}$} & Exclusion & $23.3^{\ldots \ldots \hbar t}$ & 59.0 & $106^{* \ldots *}$ & $301.3^{\ldots \ldots *}$ \\
\hline & Season & 12.9 ** & 7.0 & $\begin{array}{l}15.2 \\
* * \\
*\end{array}$ & 6.1 \\
\hline & $\begin{array}{l}\text { Exclusion: } \\
\text { Season }\end{array}$ & 5.6 & $14.5^{* *}$ & $\underset{k * *}{28.8}$ & $27.0^{* * * *}$ \\
\hline \multirow{3}{*}{$\begin{array}{l}\text { Visitation rate } \\
\text { models }\end{array}$} & Visitation rate & $5.0 *$ & 3.6 . & 1.5 & $7.2^{* *}$ \\
\hline & Season & 7.6 & $10.9^{*}$ & 21.8 & $8.4^{*}$ \\
\hline & $\begin{array}{l}\text { Visitation rate: } \\
\text { Season }\end{array}$ & 0.5 & 0.3 & 2.7 & 4.2 \\
\hline \multirow{3}{*}{$\begin{array}{l}\text { Spatial CV of } \\
\text { visitation } \\
\text { rate models }\end{array}$} & $\begin{array}{l}\text { Spatial CV of } \\
\text { visitation rate }\end{array}$ & 2.5 & $6.5^{*}$ & 3.8 & 3.4 \\
\hline & Season & $13.4^{* *}$ & $10.3^{*}$ & $\begin{array}{l}15.6 \\
* k\end{array}$ & 4.8 \\
\hline & $\begin{array}{l}\text { Spatial CV of } \\
\text { visitation rate: } \\
\text { Season }\end{array}$ & 1.3 & 7.1 . & 6.4 & 10.8 \\
\hline
\end{tabular}

$$
\begin{aligned}
& \quad: p<0.1 \\
& { }^{*}: \mathrm{p}<0.05 \\
& { }_{* *}: \mathrm{p}<0.01 \\
& \quad: \mathrm{p}<0.001
\end{aligned}
$$

\section{Table 2}

- Chisq (exclusion models) and F- values (visitation rate - mean and CV models) of each predictor variable of the 'spatial variation' models. Chisq, F- and p- values are calculated with the Anova function of the car package. Chisq or F-

\begin{tabular}{|c|c|c|c|c|c|}
\hline & \multirow[b]{2}{*}{ Predictor } & \multicolumn{2}{|l|}{ Pear } & \multicolumn{2}{|c|}{ Apple } \\
\hline & & $\begin{array}{l}\text { Fruit } \\
\text { set }\end{array}$ & $\begin{array}{l}\text { Temporal } \\
\text { CV of fruit } \\
\text { set }\end{array}$ & $\begin{array}{l}\text { Fruit } \\
\text { set }\end{array}$ & $\begin{array}{l}\text { Temporal } \\
\text { CV of fruit } \\
\text { set }\end{array}$ \\
\hline $\begin{array}{l}\text { Exclusion } \\
\text { treatment } \\
\text { models }\end{array}$ & Exclusion & $\begin{array}{l}28.4 \\
* * *\end{array}$ & $17.4^{* k *}$ & $\begin{array}{l}\mathbf{5 2 . 4} \\
* * *\end{array}$ & $44.6^{* * *}$ \\
\hline $\begin{array}{l}\text { Visitation rate } \\
\text { models }\end{array}$ & $\begin{array}{l}\text { Visitation } \\
\text { rate }\end{array}$ & 1.9 & $17.2^{*}$ & 0.4 & 1.2 \\
\hline $\begin{array}{c}\text { Temporal CV } \\
\text { of visitation } \\
\text { rate models }\end{array}$ & $\begin{array}{l}\text { Temporal CV } \\
\text { of visitation } \\
\text { rate }\end{array}$ & 5.1 . & $12.0^{*}$ & 0.1 & 0.2 \\
\hline
\end{tabular}
values whose p-values are lower than 0.05 are shown in bold type; chisq or Fvalues whose p-values are lower than 0.1 are in italics. In the exclusion treatment model of apples, fruit set was log transformed to achieve normality.

\section{Results}

\subsection{Trends in visitation rate}

The total number of observed visits differed greatly between the first two and the last two seasons, probably due to the different pollinator sampling methodologies. In flowering seasons 2016 and 2017, we observed a total of 548 visits to 45,810 flowers over a total of $2180 \mathrm{~h}$ of pear and apple flower monitoring, while in seasons 2018 and 2019 we observed a total of 10371 visits to 41,423 flowers over a total of $629 \mathrm{~h}$. Apis mellifera accounted for almost all (99.7\%) the visits to flowers of both crops. Visitation rate (visits per flower $\mathrm{x} 10 \mathrm{~min}^{\wedge}-1$ ) was almost one order of magnitude higher in apple than in pear trees for both seasons 2016 and 2017 (apple mean \pm SD: $0.092 \pm 0.006$, pear: $0.013 \pm 0.001$ ) and seasons 2018 and 2019 (apple mean \pm SD: $0.36 \pm 0.02$, pear: $0.067 \pm 0.006$ ).

\subsection{Effects of pollinator exclosure}

In both crops the exclusion of pollinators had a statistically significant effect on mean fruit set (Tables 1 and 2, Fig. 3) and its spatial and temporal CV (Tables 1 and 2, Fig. 4). In pears we estimated a decrease of $50 \%$ in mean fruit set among pollinator-excluded flowers in both spatial and temporal models (Tables S2 and S3). In apples the exclusion treatment interacted with season (spatial models), so there were two years with reductions of almost 100\% due to the exclusion (2016 and 2018) and one with a reduction of $30 \%$ (2019). Overall, we estimated a decrease in mean fruit set of $71 \%$ in excluded flowers (Table S2). In the temporal models, we estimated a decrease of $92 \%$ in the apple fruit set of excluded flowers (Table S3).

The spatial CV of fruit set strongly increased in both crops with pollinator exclusion, although this variable interacted with season (Fig. 4a, b). In pears we estimated an increase of between $155 \%$ and $496 \%$ in fruit set CV due to pollinator exclusion. In apples the estimated increase in the CV of fruit set due to exclusion was $248 \%$ and $495 \%$, depending on the season (Table S2). Overall, the increase in fruit set spatial CV for the excluded flowers was $296 \%$ in pears and $385 \%$ in apples. The temporal CV of fruit set increased with exclusion by $197 \%$ for pears and $329 \%$ for apples (Fig. 4c,d, Table S3).

\subsection{Effects of mean visitation rate}

In the spatial models, the effects of mean visitation rate on fruit set (mean and spatial CV) were different in pears and apples. In pears we 

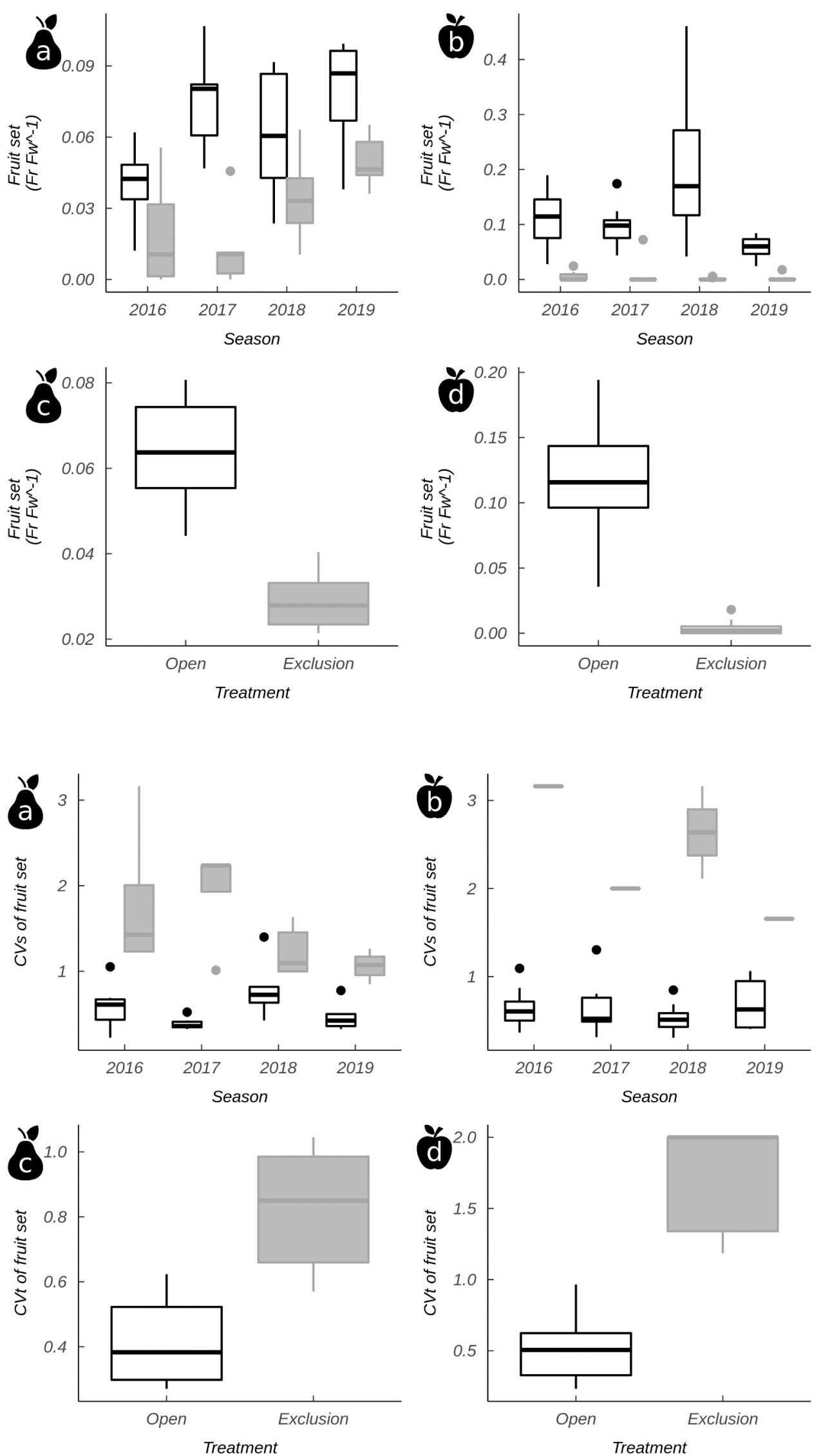

Fig. 3. - Effect of pollinator exclosure on mean fruit set of pears and apples. Left panels: pears, right panels: apples. (a) and (b) illustrate the data used for the 'spatial variation models'; (c) and (d) show the data used for the 'temporal variation models'. White boxes: open treatment, gray boxes: exclusion treatment. Boxes show the inter-quartile range (IQR), horizontal lines represent the median, and whiskers show the range of $1.5 * I Q R$. Mean fruit set $=$ fruit $\mathrm{x}$ flower ${ }^{\wedge}-1$. Note the difference in scales on the $y$ axis between crops.

Fig. 4. - Effect of pollinator exclosure on the spatial and temporal coefficients of variation (CV) of fruit set in pears and apples. (a) and (b) illustrate the data used for the 'spatial variation models'; (c) and (d) show the data used for the 'temporal variation models'. White boxes: open treatment, gray boxes: exclusion treatment. Boxes show the inter-quartile range (IQR), horizontal lines represent the median, and whiskers show the range of $1.5 *$ IQR. Fruit set $=$ Fruit $\mathrm{x}$ Flower ${ }^{\wedge}-1, \mathrm{CV}=$ standard deviation over mean. 
found a statistically significant increase in mean fruit set of 0.4 per unit of visitation rate (Fig. 2-A2, Table S2), while in apples mean visitation rate had a significant effect on the spatial CV of fruit set (Table 1, Fig. 2B4). This effect was contrary to our predictions (i.e., spatial CV of fruit set increased 0.9 units per unit of visitation rate, Table S2). Interaction between mean visitation rate and season was non-significant for all models (Table 1).

Surprisingly, analysis of the temporal models did not show any significant effect of visitation rate on mean fruit set in either crop (Fig. 2-A3 and A5) or on the temporal CV of apple fruit set (Fig. 2-B5). However, we did find a statistically significant effect of mean visitation rate on the temporal CV of fruit set in pears (Fig. 2-B3, Table 2), as it decreased by 0.36 units per unit increase in visitation rate (Table S3).

\subsection{Effects of $C V$ of visitation rate}

In the spatial models we found no statistically significant association between the spatial CV of visitation rate and the mean fruit set of either crop (Table 1 and Fig. 2-C2 and C4). Regarding the effect of the spatial $\mathrm{CV}$ of visitation rate on the fruit set $\mathrm{CV}$, in pears we found a significant positive effect (an increase of 0.3 units per unit of visitation rate $\mathrm{CV}$, Table S2, Fig. 2-D2) while in apples there was no significant effect (Table 1, Fig. 2-D4). Finally, in the temporal models the effect of the temporal visitation rate $\mathrm{CV}$ on fruit set (mean or temporal CV) was statistically significant only for the pear fruit set CV, showing an increase of 0.4 units per unit of visitation rate CV (Table 2, S3 and Fig. 2C3, D3, C5 and D5).

\section{Discussion}

Our results show the important contribution of insect pollination to mean yield and yield stability over space and time in pears and apples. Despite homogeneous, managed watering and fertilization, large spatial and temporal variability was found in the pollination and yield of both crops. We found that the absence of pollinators decreased mean fruit set (Fig. 3) and increased its spatial and temporal variability (Fig. 4). Regarding the role of pollinator (honey bee) visits, the effect of mean visitation rate or their CVs on fruit set (mean and CVs) differed between the crops studied (Fig. 2).

The exclusion treatment simulates a "no pollinator" scenario. In the case of pears, we observed that it reduced fruit set by $50 \%$ in both spatial and temporal models. Moreover, this became more variable, the spatial and temporal CV of fruit set increasing by $296 \%$ and $197 \%$ with pollinator exclusion, respectively (Table S2 and Table S3). In apples, pollinator exclusion led not only to a greater reduction in fruit set than for pears (71\% in spatial models and $92 \%$ in temporal models) but also to a more marked increase in spatial (385\%) and temporal (329\%) CV (Tables S2 and S3). This notable reduction in fruit set in both crops is consistent with their categorization as crops whose pollinator dependence is "great" (Klein et al., 2007). However, this category encompasses a wide range of pollinator dependencies (i.e., reductions in yield of between $40 \%$ and $90 \%$ ). According to our results, fruit set in apples is more pollinator-dependent than in pears, almost reaching the category where the contribution of pollinators is "essential" (i.e., a reduction equal to or more than $90 \%$ in the absence of pollinators). Moreover, we showed that pollinators not only contribute to an increase in fruit set in both crops (Fig. 3), but also, and even more strongly, contribute to a reduction in spatial and temporal yield variability (Fig. 4). The difference in the magnitude of this effect between crops may suggest that the greater the contribution of pollinators to producing fruits in a crop, the greater their contribution to yield stability in space and time. While the correlation between crop pollinator dependence and the temporal variability of yield has been documented on a global scale (Garibaldi et al., 2011a), the relation with spatial variability shown here warrants further testing on different spatial scales.

Although the scenario of "no pollinators" is hypothetical, many agricultural systems throughout the world are managed under conventional intensification, relying exclusively on hiring beehives to supply pollination demand (Klein et al., 2007, 2015; Ellis, 2012). This is the case of our study system, where $\sim 99 \%$ of the insects visiting flowers were managed honeybees (Geslin et al., 2017; Hünicken et al., 2020; Pérez-Méndez et al., 2020). These results should serve as a warning that agricultural practices should be adjusted in order to ensure the presence of viable populations of wild pollinators, not only to increase crop yields but also to guarantee the spatial and temporal stability of these yields (see more detailed discussion below).

When we took the mean visitation rate or their CV as predictors, we found dissimilar effects between the fruit crops. In the case of pears, the effect of visitation rate on mean fruit set was statistically significant and consistent with our expectations (i.e., mean visitation rate increased mean fruit set (Fig. 2-A2, Table 1 and Table S2). Furthermore, the visitation rate spatial CV increased the fruit set spatial CV (Fig. 2-D2). A similar result was reported by Klein (2009) for bee-pollinated coffee: spatial variation in bee species richness on a farm scale decreased the mean fruit set and increased its spatial variation. In addition, the fruit set temporal CV decreases with an increase in visitation rate, and increases with an increase in the variability of visitation rate (Fig. 2-B3 and D3). Overall, the effects of pollination and its spatial and temporal variability in pears cannot be disregarded, as it is one of the major factors moderating fruit yield and stability, as shown here.

In the case of apples, the only statistically significant correlation between spatial variation in fruit set and visitation rate was contrary to our prediction (i.e., higher visitation rate was related to higher spatial $\mathrm{CV}$ in fruit set, Fig. 2-B4). One explanation could be that the visits received by apple blossoms were sufficient for optimal pollination, thus their high variation was compensated for. In fact, previous studies support this explanation, at least for the mean fruit set value. Hünicken et al. (2020) reported no effect of visitation rate on apple mean fruit set in this system, while the estimated visitation rate necessary for adequate pollination ( 0.092 visits per flower x $10 \mathrm{~min}^{\wedge}-1$, Vicens and Bosch, 2000, Garibaldi et al., 2020) was exceeded by the first decile of visits to apple flowers in our study ( 0.14 visits per flower $\left.\mathrm{x} 10 \mathrm{~min}^{\wedge}-1\right)$.

Our results suggest that producers should adopt practices that promote stability in visitation rates in order to improve mean crop yield and its stability. For instance, placing small groups of beehives throughout a farm could enhance the spatial stability of visits, as each tree would be close to a hive (Cunningham et al., 2016). A study in the faba bean (Vicia $\mathrm{faba}$ ) found that yield was higher and its spatial variation lower in plants close to hives (Cunningham and Le Feuvre, 2013). Additionally, it is important to guarantee good quality beehives over the seasons, as this has a direct effect on the mean yield of pears and apples (Geslin et al., 2017). However, the management of honeybees alone is not sufficient for optimal pollination (Garibaldi et al., 2013, 2020).

While our study system relies exclusively on honey bee visits, a diverse pollinator assemblage can improve the mean yield and spatial or temporal stability of pollinator-dependent crops through several mechanisms. For example, spatial stability on a farm scale may be enhanced by different pollinator species since they are likely to have differing flight ranges and complement each other by visiting different sectors of the farm (Woodcock et al., 2013; Garratt et al., 2018). It is also possible that a species enhances its pollination efficacy in the presence of another species, via behavioral changes (Brittain et al., 2013; Eeraerts et al., 2020; Winfree and Kremen, 2009; Woodcock et al., 2013). Temporal stability between seasons could be improved due to natural uncoupled fluctuations in population abundance among different species (e.g., species that respond differently to rainy years) (Hoehn et al., 2008; Blüthgen and Klein, 2011). A previous study in this system reported that apple yield increased with the presence of both a native bumble bee and honeybees in comparison to honeybees alone (Pérez-Méndez et al., 2020). Furthermore, Kremen et al. (2004) found that both the amount and stability of watermelon pollination by native bees increased with the proportion of natural habitat in the landscape, 
and recommended the conservation of these habitats to reduce farmers' reliance on managed honeybees; this would reduce both production costs and risks to farmers, while increasing not only food security for society (Garibaldi et al., 2011b), but also biodiversity in agricultural landscapes. All in all, high variability in yield can be reduced by boosting pollinator diversity, which highlights the importance of insect pollination, as shown by previous studies (Klein, 2009; Geeraert et al., 2020). Hence, producers should go beyond one species of managed pollinator and incorporate changes in land use to enrich the pollinator assemblage.

It is important to consider the social and economic consequences of yield variability, given that food stability is a dimension of food security (McGuire et al., 2015; Pinstrup-Andersen, 2009). On the producers' side, unstable harvests imply unpredictable monetary income and lead to variability in market supply. On the consumers' side, this instability has two major consequences: fluctuations in the offer of food and volatility of prices (Wheeler and von Braun, 2013; Wossen et al., 2018). While the effect of pollination on production has been evaluated in economic terms on different scales (Gallai et al., 2009; Giannini et al., 2020; Garratt et al., 2014; Borges et al., 2020; Geslin et al., 2017), the implications of variability in the pollination service for the farmers' profit and the market price warrants more attention.

\section{Conclusion}

Year after year, producers managing homogeneous crop systems invest strongly in fertilization and pest control. However, when cultivating pollinator-dependent crops, these systems seem to present great variability in yield due to fluctuations and deficiencies in pollinator visits to crop flowers. The results presented here demonstrate the importance of management practices that promote sufficient, stable pollination services that generate yields which are not only higher, but also more stable.

\section{Funding}

This work was supported by the Consejo Nacional de Investigaciones Científicas y Técnicas, Argentina (PDTS, Res 298/14, Exp 374 8383/13), the Agencia Nacional de Promoción Científica y Tecnológica, Argentina (PICT 2015-2333 and PICT 2018-00941), the Universidad Nacional de Río Negro, Argentina (PI 40-B-567) and the 2017-2018 Belmont Forum and BiodivERsA joint call for research proposals (under the BiodivScen ERA-Net COFUND programme and with the funding organizations AEI, Spain, NWO, Netherlands, ECCyT, Argentina and NSF, USA). CLM and MAA acknowledge the support of the SURPASS2 project funded under the Newton Fund Latin America Biodiversity Programme: Biodiversity-Ecosystem Services for Sustainable Development, grants awarded by the Natural Environment Research Council of Great Britain (NERC) [NE/S011870/1], CONICET, Argentina [RD 1984/19], FAPESP, Brazil, and CONICYT, Chile.

\section{CRediT authorship contribution statement}

LAG and PLH conceived the idea and LAG, GA, NG and PLH designed the study. PLH, NG and GA collected the data. PLH analyzed the data with substantial input from LAG. PLH and CLM led the writing of the manuscript with input from MAA. All authors gave final approval for publication.

\section{Declaration of Competing Interest}

The authors declare that they have no known competing financial interests or personal relationships that could have appeared to influence the work reported in this paper.

\section{Acknowledgments}

We thank the owners and managers of the farms for opening their doors. We are also grateful to Grecia de Groot who made valuable comments on a previous version of the manuscript, and Adrián González Chaves, Maria Ramos, Dulce Gómez Carella, Tatiana Machado de Souza, Eduardo Moreira, Rafaela Santos, Alberto Girotto, Joana Ferreira and Grecia de Groot, who assisted in the field.

\section{Appendix A. Supporting information}

Supplementary data associated with this article can be found in the online version at doi:10.1016/j.agee.2021.107573.

\section{References}

Aizen, M.A., Garibaldi, L.A., Cunningham, S.A., Klein, A.M., 2008. Long-term global trends in crop yield and production reveal no current pollination shortage but increasing pollinator dependency. Curr. Biol. 18 (20), 1572-1575. https://doi.org/ 10.1016/j.cub.2008.08.066.

Aizen, M.A., Garibaldi, L.A., Cunningham, S.A., Klein, A.M., 2009. How much does agriculture depend on pollinators? Lessons from long-term trends in crop production. Ann. Bot. 103 (9), 1579-1588. https://doi.org/10.1093/aob/mcp076.

Avellá, B., Landriscini, S.G., Preiss, O., 2018. Complejo frutícola de Río Negro y Neuquén. Exportaciones, principales competidores y factores que condicionan la competitividad. Rev. Interdiscip. De Estud. Agrar. 48, 93-126.

Blüthgen, N., Klein, A.M., 2011. Functional complementarity and specialisation: the role of biodiversity in plant-pollinator interactions. Basic Appl. Ecol. 12 (4), 282-291. https://doi.org/10.1098/rspb.2012.2767.

Borges, R.C., Brito, R.M., Imperatriz-Fonseca, V.L., Giannini, T.C., 2020. The value of crop production and pollination services in the eastern Amazon. Neotrop. Entomol. 49 (4), 545-556. https://doi.org/10.1007/s13744-020-00791-w.

Brittain, C., Williams, N., Kremen, C., Klein, A.-M., 2013. Synergistic effects of non-Apis bees and honey bees for pollination services. Proc. Biol. Sci. 280, 20122767 https:// doi.org/10.1016/j.baae.2010.11.001.

Cabrera, A.L., Willink, A., 1973. Biogeografía de América Latina. Organización de Estados Americanos, Washington DC, USA.

Cunningham, S.A., Le Feuvre, D., 2013. Significant yield benefits from honeybee pollination of faba bean (Vicia faba) assessed at field scale. Field Crop. Res. 149, 269-275. https://doi.org/10.1016/j.fcr.2013.05.019.

Cunningham, S.A., Fournier, A., Neave, M.J., Le Feuvre, D., 2016. Improving spatial arrangement of honeybee colonies to avoid pollination shortfall and depressed fruit set. J. Appl. Ecol. 53 (2), 350-359. https://doi.org/10.1111/1365-2664.12573.

Dainese, M., Martin, E.A., Aizen, M.A., Albrecht, M., Steffan-Dewenter, I., 2019. A global synthesis reveals biodiversity-mediated benefits for crop production. Sci. Adv. 5, 0121. https://doi.org/10.1126/sciadv.aax0121.

Deguines, N., Jono, C., Baude, M., Henry, M., Julliard, R., Fontaine, C., 2014. Large-scale trade-off between agricultural intensification and crop pollination services. Front. Ecol. Environ. 12 (4), 212-217. https://doi.org/10.1890/130054.

Díaz, P.C., Arenas, A., Fernández, V.M., Susic Martin, C., Basilio, A.M., Farina, W.M., 2013. Honeybee cognitive ecology in a fluctuating agricultural setting of apple and pear trees. Behav. Ecol. 24 (5), 1058-1067. https://doi.org/10.1093/beheco/ art026.

Eeraerts, M., Smagghe, G., Meeus, I., 2020. Bumble bee abundance and richness improves honey bee pollination behaviour in sweet cherry. Basic and Appl. Ecol. 43, 27-33. https://doi.org/10.1016/j.baae.2019.11.004.

Ellis, J., 2012. The honey bee crisis. Outlooks Pest Manag. 23 (1), 35-40. https://doi. org/10.1564/22feb10.

Farkas, A., Orosz-Kovács, Z., 2003. Nectar secretion dynamics of Hungarian local pear cultivars. Plant Syst. Evol. 238 (1-4), 57-67. https://doi.org/10.1007/s00606-0030268-7.

Foley, J.A., DeFries, R., Asner, G.P., Barford, C., Bonan, G., Carpenter, S.R., Helkowski, J. H., 2005. Global consequences of land use. Science 309 (5734), 570-574. https:// doi.org/10.1126/science.1111772.

Fox \& Weisberg, 2011. An $\{\mathrm{R}\}$ Companion to Applied Regression, second ed. Sage, Thousand Oaks CA (URL). 〈http://socserv.socsci.mcmaster.ca/jfox/Books/Compan ion.

Gallai, N., Salles, J.M., Settele, J., Vaissière, B.E., 2009. Economic valuation of the vulnerability of world agriculture confronted with pollinator decline. Ecol. Econ. 68 (3), 810-821. https://doi.org/10.1016/j.ecolecon.2008.06.014.

Garibaldi, L.A., Aizen, M.A., Klein, A.M., Cunningham, S.A., Harder, L.D., 2011a. Global growth and stability of agricultural yield decrease with pollinator dependence. Proc. Natl. Acad. Sci. U.S.A. 108 (14), 5909-5914. https://doi.org/10.1073/ pnas. 1012431108.

Garibaldi, L.A., Steffan-Dewenter, I., Kremen, C., Morales, J.M., Bommarco, R., Cunningham, S.A., Holzschuh, A., 2011b. Stability of pollination services decreases with isolation from natural areas despite honey bee visits. Ecol. Lett. 14 (10), 1062-1072. https://doi.org/10.1111/j.1461-0248.2011.01669.x.

Garibaldi, L.A., Steffan-Dewenter, I., Winfree, R., Aizen, M.A., Bommarco, R., Cunningham, S.A., Bartomeus, I., 2013. Wild pollinators enhance fruit set of crops 
regardless of honey bee abundance. Science 339 (6127), 1608-1611. https://doi. org/10.1126/science.1230200.

Garibaldi, L.A., Sáez, A., Aizen, M.A., Fijen, T., Bartomeus, I., 2020. Crop pollination management needs flower-visitor monitoring and target values. J. Appl. Ecol. 57 (4), 664-670. https://doi.org/10.1111/1365-2664.13574.

Garratt, M.P., Breeze, T.D., Jenner, N., Polce, C., Biesmeijer, J.C., Potts, S.G., 2014. Avoiding a bad apple: Insect pollination enhances fruit quality and economic value. Agric., Ecosyst. Environ. 184, 34-40. https://doi.org/10.1016/j.agee.2013.10.032.

Garratt, M.P.D., Brown, R., Hartfield, C., Hart, A., Potts, S.G., 2018. Integrated crop pollination to buffer spatial and temporal variability in pollinator activity. Basic Appl. Ecol. 32, 77-85. https://doi.org/10.1016/j.baae.2018.06.005.

Geeraert, L., Aerts, R., Berecha, G., Daba, G., De Fruyt, N., D'hollander, J., Honnay, O., 2020. Effects of landscape composition on bee communities and coffee pollination in Coffea arabica production forests in southwestern Ethiopia. Agric. Ecosyst. Environ. 288, 106706 https://doi.org/10.1016/j.agee.2019.106706.

Geslin, B., Aizen, M.A., Garcia, N., Pereira, A.J., Vaissière, B.E., Garibaldi, L.A., 2017. The impact of honey bee colony quality on crop yield and farmers' profit in apples and pears. Agric. Ecosyst. Environ. 248, 153-161. https://doi.org/10.1016/j. agee.2017.07.035.

Giannini, T.C., Costa, W.F., Borges, R.C., Miranda, L., da Costa, C.P.W., Saraiva, A.M., Fonseca, V.L.I., 2020. Climate change in the Eastern Amazon: crop-pollinator and occurrence-restricted bees are potentially more affected. Reg. Environ. Change 20 (1), 9. https://doi.org/10.1007/s10113-020-01611-y.

Hoehn, P., Tscharntke, T., Tylianakis, J.M., Steffan-Dewenter, I., 2008. Functional group diversity of bee pollinators increases crop yield. Proc. R. Soc. B: Biol. Sci. 275 (1648), 2283-2291. https://doi.org/10.1098/rspb.2008.0405.

Hünicken, P.L., Morales, C.L., García, N., Garibaldi, L.A., 2020. Insect pollination, more than plant nutrition, determines yield quantity and quality in apple and pear. Neotrop. Entomol. 1-8. https://doi.org/10.1007/s13744-020-00763-0.

Jackson, J.E., 2003. The Biology of Apples and Pears. Cambridge University Press, Cambridge, pp. 268-317. 〈www.cambridge.org/9780521380188〉.

Krebs, J.R., Wilson, J.D., Bradbury, R.B., Siriwardena, G.M., 1999. The second silent spring? Nature 400 (6745), 611-612. https://doi.org/10.1038/23127.

Kremen, C., Williams, N.M., Bugg, R.L., Fay, J.P., Thorp, R.W., 2004. The area requirements of an ecosystem service: crop pollination by native bee communities in California. Ecol. Lett. 7 (11), 1109-1119. https://doi.org/10.1111/j.14610248.2004.00662.x.

Klein, A.M., Vaissiere, B.E., Cane, J.H., Steffan-Dewenter, I., Cunningham, S.A., Kremen, C., Tscharntke, T., 2007. Importance of pollinators in changing landscapes for world crops. Proc. R. Soc. B: Biol. Sci. 274 (1608), 303-313. https://doi.org/ 10.1098/rspb.2006.3721.

Klein, A.M., 2009. Nearby rainforest promotes coffee pollination by increasing spatiotemporal stability in bee species richness. For. Ecol. Manag. 258 (9), 1838-1845. https://doi.org/10.1016/j.foreco.2009.05.005.

Klein, A.M., Hendrix, S.D., Clough, Y., Scofield, A., Kremen, C., 2015. Interacting effects of pollination, water and nutrients on fruit tree performance. Plant Biol. 17 (1), 201-208. https://doi.org/10.1111/plb.12180.
Maccagnani, B., Ladurner, E., Santi, F., Burgio, G., 2003. Osmia cornuta (Hymenoptera, Megachilidae) as a pollinator of pear (Pyrus communis): fruit-and seed-set. Apidologie 34 (3), 207-216. https://doi.org/10.1051/apido:2003009.

Maccagnani, B., Burgio, G., Stanisavljevic, L.Z., Maini, S., 2007. Osmia cornuta management in pear orchards. Bull. Insect 60 (1), 77. 〈https://bit.ly/3our7D7〉.

McGuire, FAO, IFAD, WFP, 2015. The state of food insecurity in the world 2015: meeting the 2015 international hunger targets: taking stock of uneven progress. Rome: FAO, 2015. Adv. Nutr. 6 (5), 623-624. https://doi.org/10.3945/an.115.009936.

Matson, P.A., Parton, W.J., Power, A.G., Swift, M.J., 1997. Agricultural intensification and ecosystem properties. Science 277 (5325), 504-509. https://doi.org/10.1126/ science.277.5325.504.

Pérez-Méndez, N., Andersson, G.K., Requier, F., Hipólito, J., Aizen, M.A., Morales, C.L., Garibaldi, L.A., 2020. The economic cost of losing native pollinator species for orchard production. J. Appl. Ecol. 57 (3), 599-608. https://doi.org/10.1111/13652664.13561.

Pinheiro, J., Bates, D., DebRoy, S., Sarkar, D., R Core Team (2016)._nlme: Linear and Nonlinear Mixed Effects Models_. R package version 3.1-124, <URL: $\langle$ http://CRAN. R-project.org $/$ package $=$ nlme $\rangle$.

Pinstrup-Andersen, P., 2009. Food security: definition and measurement. Food Secur. 1 (1), 5-7. https://doi.org/10.1007/s12571-008-0002-y.

Ramírez, F., Davenport, T.L., 2013. Apple pollination: a review. Sci. Hortic. 162, 188-203. https://doi.org/10.1016/j.scienta.2013.08.007.

R Core Team, 2018. R: A Language and Environment for Statistical Computing. R Foundation for Statistical Computing, Vienna, Austria. 〈https://www.R-project. $\operatorname{org} /\rangle$.

Rubio, G., Zhu, J., Lynch, J.P., 2003. A critical test of the two prevailing theories of plant response to nutrient availability. Am. J. Bot. 90, 143-152. https://doi.org/10.3732/ ajb.90.1.143.

Ruel, J.J., Ayres, M.P., 1999. Jensen's inequality predicts effects of environmental variation. Trends Ecol. Evol. 14 (9), 361-366. https://doi.org/10.1016/S0169-5347 (99)01664-X.

Vicens, N., Bosch, J., 2000. Pollinating efficacy of Osmia cornuta and Apis mellifera (Hymenoptera: Megachilidae, Apidae) on 'red Delicious' apple. Environ. Entomol. 29 (2), 235-240. https://doi.org/10.1093/ee/29.2.235.

Wheeler, T., von Braun, J., 2013. Climate change impacts on global food security. Science 7341 (6145), 508-513. https://doi.org/10.1126/science.1239402.

Winfree, R., Kremen, C., 2009. Are ecosystem services stabilized by differences among species? A test using crop pollination. Proc. R. Soc. B: Biol. Sci. 276 (1655), 229-237. https://doi.org/10.1098/rspb.2008.0709.

Woodcock, B.A., Edwards, M., Redhead, J., Meek, W.R., Nuttall, P., Falk, S., Pywell, R.F., 2013. Crop flower visitation by honeybees, bumblebees and solitary bees: Behavioural differences and diversity responses to landscape. Agric. Ecosyst. Environ. 171, 1-8. https://doi.org/10.1016/j.agee.2013.03.005.

Wossen, T., Berger, T., Haile, M.G., Troost, C., 2018. Impacts of climate variability and food price volatility on household income and food security of farm households in East and West Africa. Agric. Syst. 163, 7-15. https://doi.org/10.1016/j. agsy.2017.02.006. 